\title{
The Role of Edge Dislocations on the Red Luminescence of ZnO Films Deposited by RF-Sputtering
}

\author{
Rocío Félix, ${ }^{1,2}$ Marco Peres, ${ }^{3,4,5}$ Sergio Magalhães, ${ }^{5}$ Maria Rosario Correia, ${ }^{3}$ \\ Armando Lourenço, ${ }^{4}$ Teresa Monteiro, ${ }^{3}$ Rafael García, ${ }^{1,2}$ and Francisco M. Morales ${ }^{1,2}$ \\ ${ }^{1}$ Department of Materials Science and Metallurgical Engineering and Inorganic Chemistry, University of Cádiz, Puerto Real, \\ 11510 Cádiz, Spain \\ ${ }^{2}$ Institute of Research on Electron Microscopy and Materials of the University of Cádiz (IMEYMAT), Puerto Real, 11510 Cádiz, Spain \\ ${ }^{3}$ Department of Physic and I3N, University of Aveiro, Campus of Santiago, 3810-193 Aveiro, Portugal \\ ${ }^{4}$ Department of Physics, CICECO, University of Aveiro, 3810-193 Aveiro, Portugal \\ ${ }^{5}$ Instituto Superior Técnico (IST), Campus Tecnológico e Nuclear, Estrada Nacional 10, Bobadela, 2695-066 Loures, Portugal
}

Correspondence should be addressed to Rocío Félix; rocio.felix@uca.es

Received 28 July 2015; Accepted 8 November 2015

Academic Editor: Run-Wei Li

Copyright (C) 2015 Rocío Félix et al. This is an open access article distributed under the Creative Commons Attribution License, which permits unrestricted use, distribution, and reproduction in any medium, provided the original work is properly cited.

\begin{abstract}
The existence of extended defects (i.e., dislocations) in inorganic semiconductors, such as $\mathrm{GaN}$ or $\mathrm{ZnO}$, responsible for broad emission peaks in photoluminescence analysis remains unresolved. The possible assignments of these luminescence bands are still matter of discussion. In this study, two different zinc oxide samples, grown under different oxygen partial pressures and substrate temperatures, are presented. Epitaxial and structural properties were analysed by means of X-ray diffraction and transmission electron microscopy techniques. They confirm that the layers are single-phase with a good crystalline quality. Nevertheless, a different density of threading dislocations, with a higher contribution of edge dislocations, was found. Photoluminescence spectroscopy has been used to investigate the optical properties. The steady state luminescence spectra performed at $14 \mathrm{~K}$ evidenced the donor bound exciton recombination and deep green and red emission bands. The red band with a maximum at $1.78 \mathrm{eV}$ was found to be stronger in the sample grown at lower oxygen pressure which also shows higher density of threading dislocations. From the temperature and excitation density dependence of the red band, a donor acceptor pair recombination model was proposed, where hydrogen and zinc vacancies are strong candidates for the donor and acceptor species, respectively.
\end{abstract}

\section{Introduction}

Nowadays $\mathrm{ZnO}$ is among other semiconductors, one of the most studied materials, due to the potentialities offered by its wide direct band gap $(3.37 \mathrm{eV})$ at room temperature and high $(\sim 60 \mathrm{meV})$ free exciton binding energy $[1,2]$. These characteristics together with the easiness of depositing thin $\mathrm{ZnO}$ films by different techniques with a considerable quality make this material a suitable semiconductor for a broad range of applications in optical and electrical devices (light emitting diodes, transparent thin film transistors, and surface acoustic wave systems [2-6]). Despite the increasing interest in this material, a deeper understanding of the role of the structural defects in the oxide host is still necessary, for example, to overcome the difficulties in obtaining p-type conductivity, among others. For instance, line defects, and more specifically threading dislocations (TDs), are known to have effects on photonic and electronic materials behaviours [7, 8] causing a degradation in the semiconductor device. For example, TDs produce undesirable phenomena that lead to the appearance of additional electronic energy levels in the band gap influencing the semiconductor electrical and optical properties [8].

From the luminescence point of view, it is well established that the recombination processes on high quality $\mathrm{ZnO}$ layers occur nearby the band gap with the emission due to free and donor bound excitons [9]. Additionally, surface excitons and stacking faults related luminescence effects have also been 


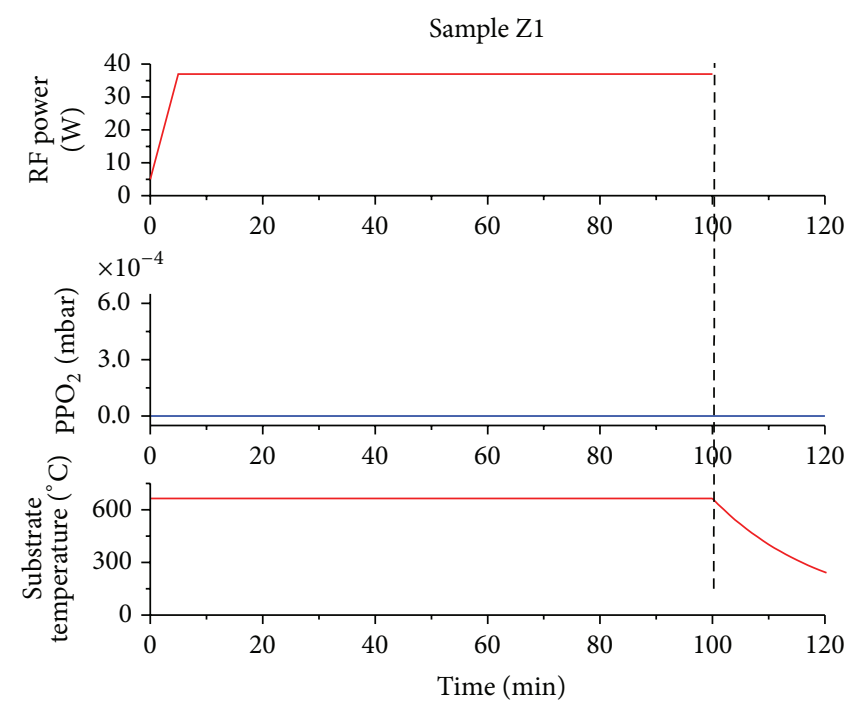

(a)

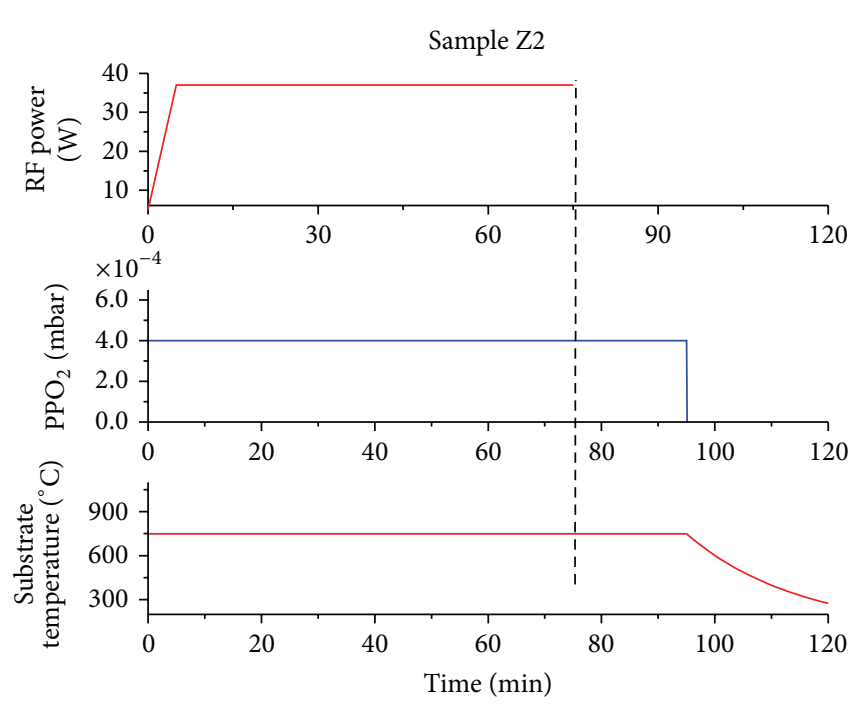

(b)

FIGURE 1: Deposition parameters profiles (substrate temperature, $\mathrm{O}_{2}$ partial pressure $\left(\mathrm{PPO}_{2}\right)$, and RF power) of sample $\mathrm{Z1}$ (a) and sample $\mathrm{Z} 2$ (b).

reported [10-12]. On the lower energy side, the luminescence has been attributed to donor acceptor pairs (DAP) and recombination's broad bands to often unknown origin [13]. The latter can occur in distinct spectral regions and have been observed in the blue, green, orange, and red spectral regions, when the samples are excited with photons with energy higher than the band gap $[2,14]$. Based on the luminescence behaviour with time, temperature, and excitation density, several models have been proposed for the emitting centres including impurity related [15-18], DAP [2, 13, 19], free-tobound transitions $[14,20,21]$ and potential fluctuations [20, 22]. The observation of the different broad bands is shown to be sample dependent and their assignment to point or structural defects are still under debate.

In this work, $\mathrm{ZnO}$ thin films were deposited by radiofrequency- (RF-) sputtering on [0001] $c-\mathrm{Al}_{2} \mathrm{O}_{3}$ for different growth parameters. The samples were characterized by diffraction-contrast two-beam transmission electron microscopy (DC-2B-TEM). Additionally, electron and Xray diffraction $(\mathrm{XRD})$, plus photoluminescence $(\mathrm{PL})$, were used in order to check correlations of structural and optical properties. The emphasis was placed on the red emission band with a maximum at $1.78 \mathrm{eV}$ which was found to be stronger in samples with higher density of TDs. A correlation between the red luminescence band and the highest TD density is discussed in the context of this paper.

\section{Experimental}

Two zinc oxide film samples ( $\mathrm{Z} 1$ and $\mathrm{Z} 2$ ) were deposited by RF-sputtering on $c$-sapphire substrate using the same RF power.

Sample Z1 was deposited in the absence of oxygen and sample Z2 with an oxygen partial pressure of $4.0 \times 10^{-4} \mathrm{mbar}$.
The $\mathrm{Z} 1$ and $\mathrm{Z} 2$ samples were grown at $664^{\circ} \mathrm{C}$ and $746^{\circ} \mathrm{C}$, respectively. These growth parameters profiles are shown in Figure 1. The distance from the target to the substrate was maintained constant and for the deposition processes a commercial $\mathrm{ZnO}$ target with a $99.9 \%$ purity was used.

Structural and optical studies were performed by transmission electron microscopy (TEM), selected area electron diffraction (SAED), XRD, and PL spectroscopy.

The structure of the samples was characterised by TEM after samples were prepared in cross sections (XTEM) or for plan-view (PVTEM). They were thinned to reach the electron transparency with conventional methods of mechanical grinding and polishing, dimpling (dimple grinder GATAN TM 656), and ion milling (applied with a GATAN low voltage precision ion polish system, PIPS). Bright field (BF) and dark field (DF) DC-2B-TEM micrographs and SAED patterns were collected with a JEOL-1200EX microscope. The TD density for each $\mathrm{ZnO}$ layer was calculated as the average value of 8 different areas sizes ranging between 0.5 and $1 \mu \mathrm{m}^{2}$ for PVTEM and 5 different lengths or regions between 0.7 and $3.7 \mu \mathrm{m}$ for XTEM preparation. The $\mathrm{ZnO}$ film thickness and surface roughness were also estimated from the analyses of 10 BF-TEM images, with analysed lengths between 12 and $30 \mu \mathrm{m}$ depending on the sample.

The XRD measurements were carried out with a Philips XRD X'pert diffractometer with the $\mathrm{Cu} \mathrm{K} \alpha$ in out-of-plane configuration for symmetric planes and in skew geometry for asymmetric ones. XRD reciprocal space maps (RSM) were obtained for the symmetric (0002) reflections and $\phi$-scans for asymmetric planes (20ㄹ1). The PL studies were carried out using a $325 \mathrm{~nm} \mathrm{He}-\mathrm{Cd}$ laser line as excitation source, and a Spex 1704 monochromator (with a 1200 grooves $/ \mathrm{mm}$ grating) coupled with a cooled photomultiplier (Hamamatsu R928) was used to disperse and detect the luminescence, respectively. The temperature dependent PL measurements 


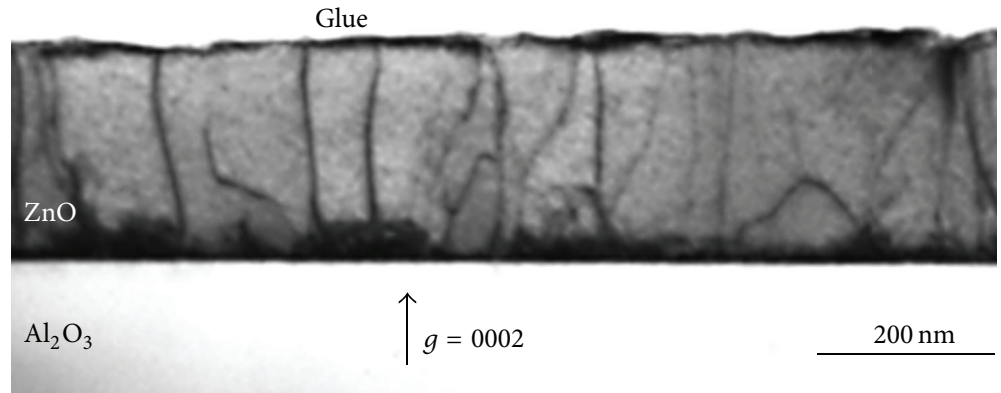

(a)

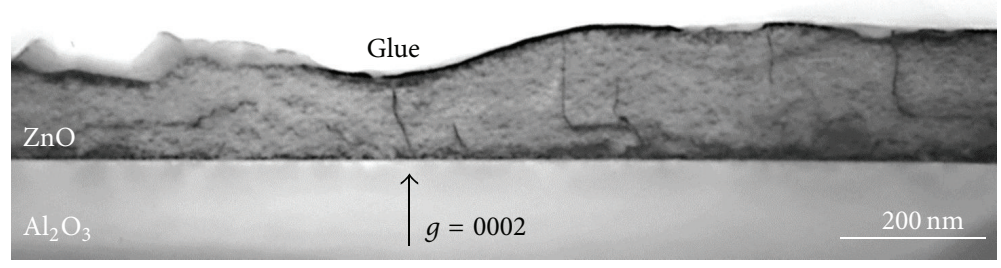

(b)

Figure 2: DC-2B-BF XTEM images of Z1 (a) and Z2 (b) samples displaying screw + mixed dislocations (they were taken in [11 20$]$ zone axis using the (0002) excited reflection).

were acquired in the temperature range between $14 \mathrm{~K}$ and room temperature (RT) using a closed-cycle-cryostat. For the excitation intensity dependence commercial calibrated neutral density filters were used. All the PL spectra were corrected to the spectral response of the collection and detection system.

\section{Results and Discussion}

3.1. Structural Properties. TEM was applied to get information about the structural quality and the presence of defects at the $\mathrm{ZnO}$ films. The thickness and surface roughness of the layers were analysed from lengths of $12 \mu \mathrm{m}$ for sample $\mathrm{Z} 1$ and $30 \mu \mathrm{m}$ for sample Z2 (see Table 1). According to a higher growth deposition time (as present in Figure 1), the $\mathrm{ZnO}$ layer in sample $\mathrm{Z} 1$ is thicker and less rough.

Concerning TD characterization by TEM, the method used in this work is based on the combination (crosscorrelation) of DC-2B-BF TEM images from XTEM and PVTEM preparations [23] which allows obtaining on the one hand edge + mixed and screw + mixed TDs and on the other hand density of TDs at different depths of the $\mathrm{ZnO}$ layers.

Images of TDs in DC-2B-TEM conditions were obtained when the samples are oriented taking into account the invisibility criterion $g \cdot b=0$. Therefore, dislocations become invisible if this criterion is satisfied, where " $g$ " is the excited reflection and " $b$ " is the Burgers vector [24]. Besides, depending on Burgers vector, TDs are classified in three different groups, that is, screw, edge, and mixed, which in the concerned wurtzite system correspond to $b_{s}=\langle 0001\rangle, b_{e}=$ $(1 / 3)\langle 11 \overline{2} 0\rangle$, and $b_{e+s}=b_{m}=(1 / 3)\langle 11 \overline{2} 3\rangle$, respectively.
TABLE 1: Thickness and roughness of $\mathrm{ZnO}$ layers for samples $\mathrm{Z} 1$ and Z2.

\begin{tabular}{lcc}
\hline Sample & Thickness $(\mathrm{nm})$ & Roughness $(\mathrm{nm})$ \\
\hline Z1 & $322 \pm 12$ & $38 \pm 12$ \\
Z2 & $195 \pm 20$ & $84 \pm 20$ \\
\hline
\end{tabular}

TABLE 2: Groups of TDs that can be observed in TEM for each preparation and two-beam conditions.

\begin{tabular}{lccc}
\hline Preparation & Zone axis & Reflection $(g)$ & Type of TDs \\
\hline PVTEM & {$[0001]$} & $(11 \overline{2} 0)$ & Edge and mixed \\
XTEM & {$[11 \overline{2} 0]$} & $(0002)$ & Screw and mixed \\
\hline
\end{tabular}

Traditionally, dislocations are given in groups (edge + mixed or screw + mixed) because images with only one type of dislocations are not geometrically possible to be obtained. For this reason, in the present work, the TD density data will be given together, that is, screw + mixed and edge + mixed. Table 2 shows the crystallographic direction (zone axis) and the related reflection $(g)$ selected to acquire the TEM images for each preparation, together with the type of TDs that are observed.

The number of TDs is directly measured from DC-2BBF TEM micrographs (a couple of examples are shown in Figures 2 and 3). Thereupon, as indicated in Table 2, edge + mixed dislocations were calculated by using the $g=(11 \overline{2} 0)$ excited reflection near the [0001] zone axis of $\mathrm{ZnO}$ from PVTEM preparations. Likewise, screw + mixed dislocations were calculated by using the (0002) excited reflection near the [11 $\overline{2} 0]$ zone axis of $\mathrm{ZnO}$ from XTEM. 
TABLE 3: TD densities at $\mathrm{ZnO}$ surface and annihilation for samples $\mathrm{Z1}$ and $\mathrm{Z} 2$.

\begin{tabular}{lccc}
\hline Sample & \multicolumn{2}{c}{ Surface dislocation densities } \\
& $\begin{array}{c}\text { Edge }+ \text { mixed } \\
\left(10^{8} \mathrm{~cm}^{-2}\right)\end{array}$ & $\begin{array}{c}\text { Screw }+ \text { mixed } \\
\left(10^{8} \mathrm{~cm}^{-2}\right)\end{array}$ \\
\hline $\mathrm{Z} 1$ & $84.9 \pm 10.3$ & $12.1 \pm 0.7$ & 44 \\
$\mathrm{Z} 2$ & $31.7 \pm 3.9$ & $4.5 \pm 0.3$ & 51 \\
\hline
\end{tabular}

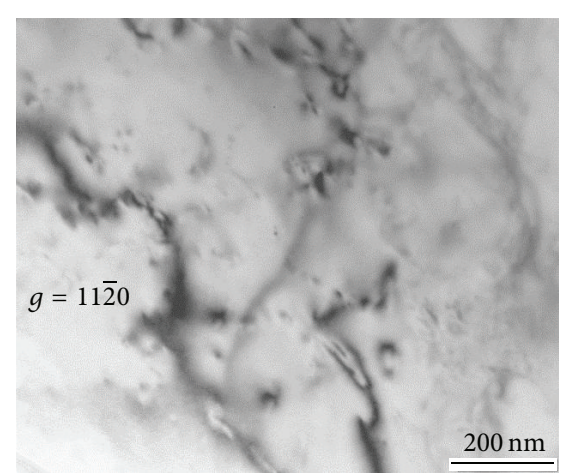

(a)

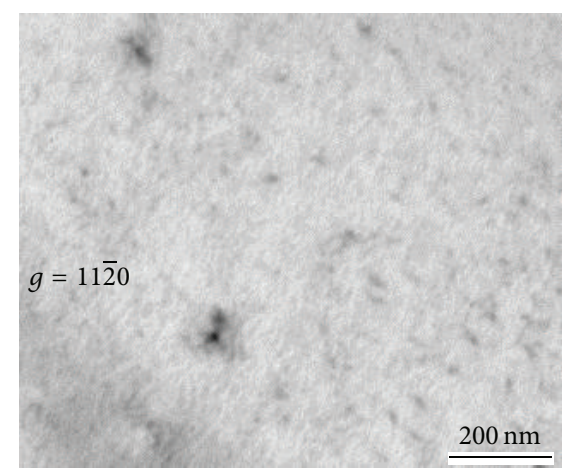

(b)

FIGURE 3: PVTEM DC-BF micrographs of Z1 (a) and Z2 (b) samples where edge + mixed dislocations are visible. They were taken using the $g=(1 \overline{1} 0)$ excited reflection.

Since it is well known that TD density values measured from PVTEM preparations are more accurate than those estimated from XTEM [25], the screw + mixed TD density on the $\mathrm{ZnO}$ surface has been determined through the edge + mixed TD density. In order to do that, we have relied on previously reported results $[26,27]$ that claim that edge + mixed dislocations are about $80-90 \%$ of the whole, while screw + mixed dislocations range between 10 and 20 per cent. Consequently, the edge + mixed TD density (directly calculated from the PVTEM preparation) is assumed as $85 \%$ of the whole, whereas the remaining percentage belongs to the screw + mixed TD density. The thickness of each XTEM preparation is evaluated by equalling the screw + mixed $\mathrm{TD}$ density directly measured value at the $\mathrm{ZnO}$ surface, to that calculated from the PVTEM. Once the thickness is determined, the density of TDs propagating from the sapphire/ZnO interface towards the $\mathrm{ZnO}$ surface (TD density

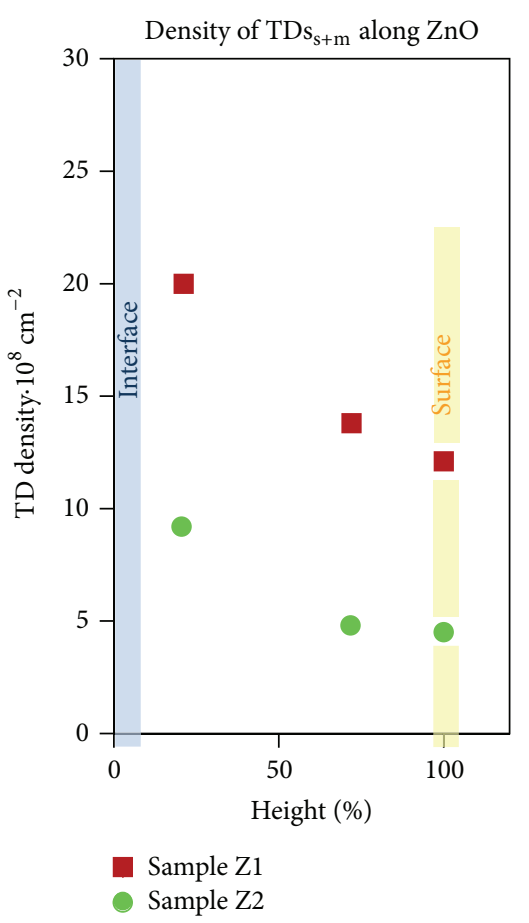

FIGURE 4: Density of screw + mixed $(s+m)$ dislocations for $\mathrm{Z} 1$ (red) and Z2 (green) samples in dependence on the distance from sapphire/ZnO interface. The densities of TDs were measured at different height rate $(20 \%, 50 \%$, and $70 \%)$ of the $\mathrm{ZnO}$ layer, where $0 \%$ belongs to sapphire/ZnO interface and $100 \%$ refers to $\mathrm{ZnO}$ surface.

evolution) can be evaluated, and therefore the annihilation rate can be estimated (see Table 3 and Figure 4). Additionally, data of TD density at $\mathrm{ZnO}$ surface obtained by using the aforementioned method are shown in Table 3. The errors in this table were calculated through the minimum square method (for the directly measured densities) and the wellknown statistical formula for mean value errors.

Evaluating the TEM results, it is found that sample $\mathrm{Z} 1$ has a higher TD density than sample Z2 (Table 3). This can be also seen in Figure 2, where pictures for Z1 and Z2 samples have the same scale marker and a higher number of screw + mixed TDs are predicted for sample $\mathrm{Z1}$ at first glance. Besides, it has been evidenced from Figures 2 and 3 that the main structural defects observed in the $\mathrm{ZnO}$ layers correspond to TDs (screw + mixed and edge + mixed) with densities ranging from $10^{8}$ to $10^{9} \mathrm{~cm}^{-2}$ from the interface to the surface (Table 3 ). These values have a good agreement with previously reported results on good quality state of the art $\mathrm{ZnO}$ layers [3, 28-30]. For the analysed samples no stacking faults were identified 


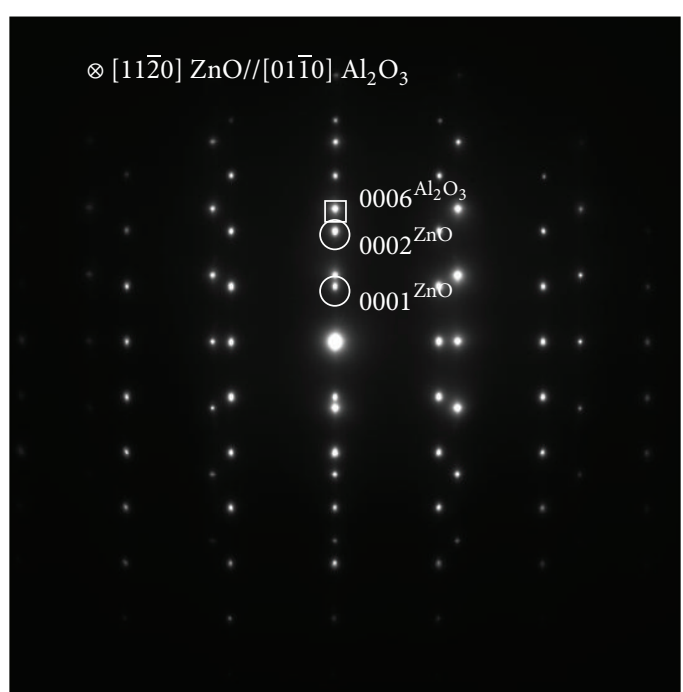

(a)

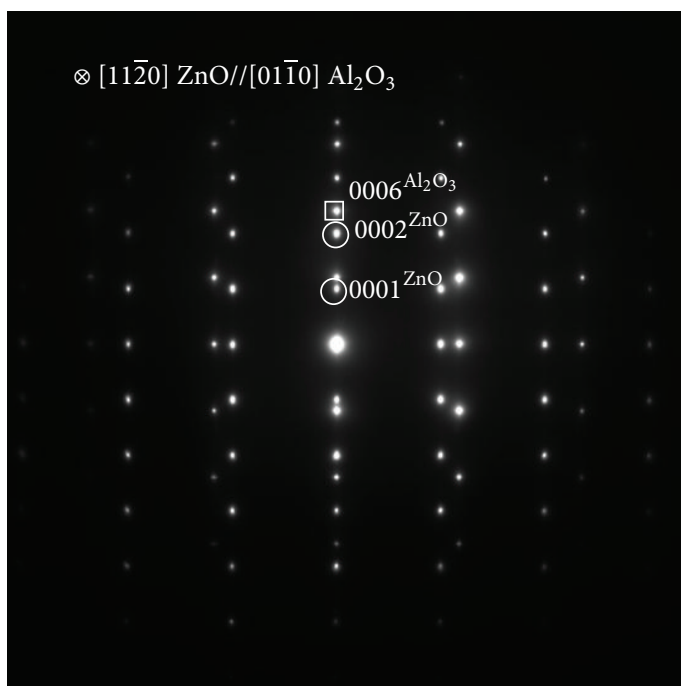

(c)

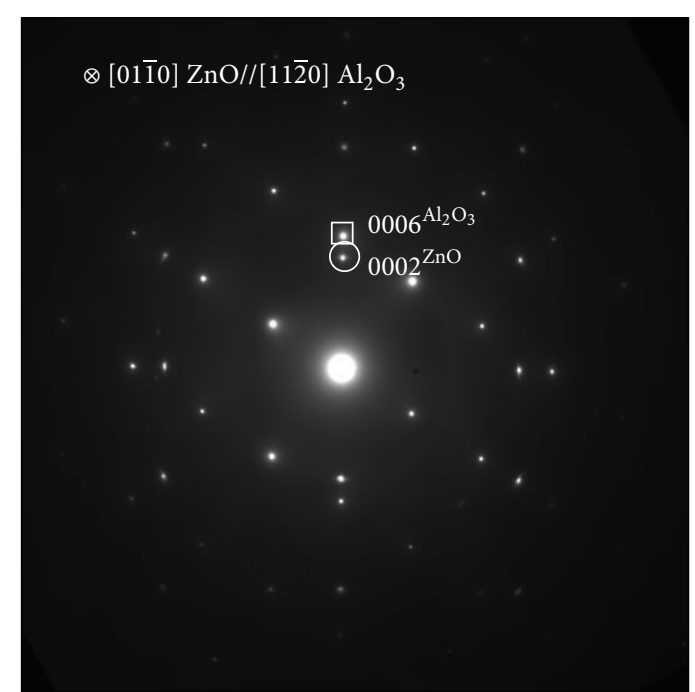

(b)

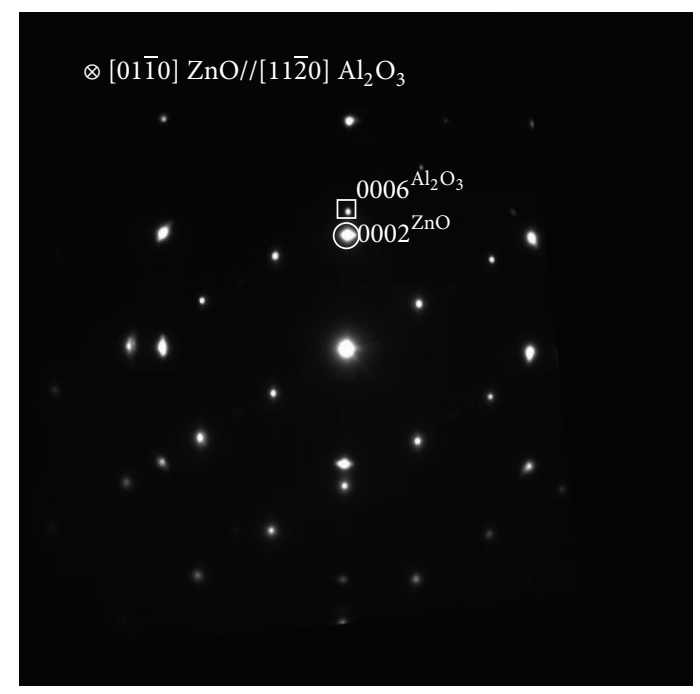

(d)

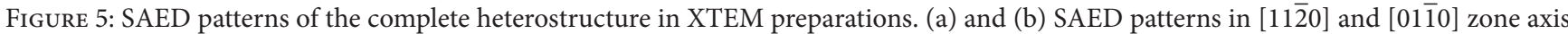

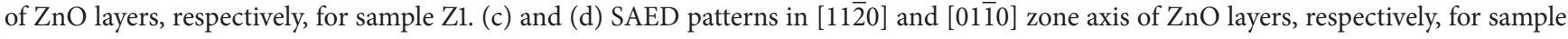
$\mathrm{Z} 2$.

and the TD density was found to be dependent on the depth inside the film. Attending to the screw + mixed annihilations, the results reveal that about $44 \%$ for sample $\mathrm{Z} 1$ and $51 \%$ in the case of sample $\mathrm{Z} 2$ annihilate when they reach the $\mathrm{ZnO}$ surface.

SAED patterns for XTEM preparations were also recorded giving indications of the good single-crystallinity of $\mathrm{ZnO}$ in regions around the $\mathrm{Al}_{2} \mathrm{O}_{3}$ and $\mathrm{ZnO}$ interface and at $\mathrm{ZnO}$ surface and of its heteroepitaxial placement on the whole heterostructure. Figure 5 shows well-defined characteristic reflections of $\mathrm{ZnO}$ wurtzite and $\alpha-\mathrm{Al}_{2} \mathrm{O}_{3}$. Therefore, the following heteroepitaxial relationships can be concluded: $[11 \overline{2} 0] \mathrm{ZnO} / /[01 \overline{1} 0] \gamma-\mathrm{Al}_{2} \mathrm{O}_{3}$ and $[01 \overline{1} 0] \mathrm{ZnO} / /[11 \overline{2} 0] \gamma-\mathrm{Al}_{2} \mathrm{O}_{3}$.
Figure 6 shows the 2 theta-omega $(2 \theta-\omega)$ scans for Z1 and $\mathrm{Z} 2$ samples. The data indicate that only one diffraction maximum attributed to the (0002) $\mathrm{ZnO}$ reflection is observed for the investigated layers. This result specifies that the crystallites grow preponderantly oriented with the $c$-axis normal to the substrate. To evaluate the samples structural quality, the RSM for the reflection (0002) were carried out as shown in Figure 7 . The shape and broadening of the symmetric RSM are very similar for both samples, indicating that the type of defects should be similar. The broadening can be accounted by stoichiometry/strain gradients, tilt, and the limited size [31]. In the investigated layers the stoichiometry/strain gradients should be one of the major effects on the broadening, as suggested by the TEM measurements. We also 


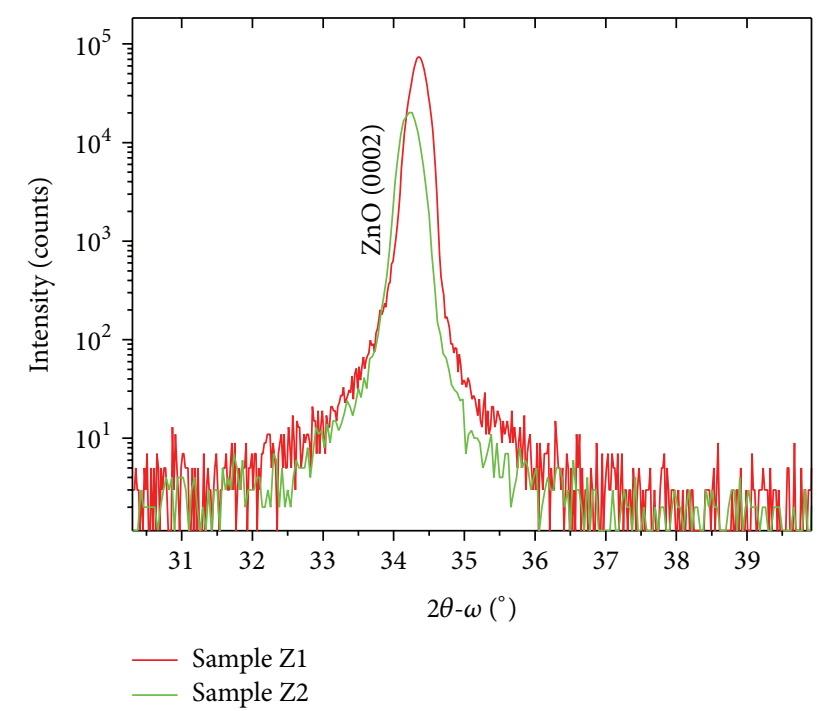

FIGURE 6: XRD 2 theta-omega scans for the reflection (0002) obtained in out-of-plane geometry for Z1 (red) and Z2 (green) samples.

performed $\phi$-scans in order to evaluate the azimuthal rotation of the crystallites by calculating the twist angle, $\alpha_{\phi}[32]$.

Figure 8 shows the $\phi$-scans of the asymmetric (20ㄹ) reflection, corresponding to a plane with an inclination angle of $74.83^{\circ}$ with respect to the [0001] direction. A distinct broadening can be clearly identified for both samples. This result evidences that dissimilar twist angles (estimated as $0.290^{\circ}$ and $0.109^{\circ}$, for samples $\mathrm{Z} 1$ and $\mathrm{Z} 2$, resp.) occur among the crystallites. Assuming that the twisted angle is proportional to the density of the edge dislocations [31, 32], these results suggest that a high density of edge dislocations is present in the sample $\mathrm{Z} 1$.

3.2. Optical Properties. Figure 9 shows the $14 \mathrm{~K}$ PL spectra of the two $\mathrm{ZnO}$ layers obtained with above band gap excitation. On the high energy side, the samples luminescence corresponds to the free (FX), donor bound $\left(\mathrm{D}^{0} \mathrm{X}\right)$ and surface (SX) excitons, followed by the two-electron satellite lines and LO-phonon replicas of the bound excitons [9, 20, 33-36]. Additionally, a structured green luminescence $(\sim 2.4 \mathrm{eV})$ and an unstructured red band $(\sim 1.78 \mathrm{eV})$ are observed. The LOphonon-assisted structured green band has been ascribed as a $\mathrm{Cu}$-impurity related defect [37]. Copper impurities are known to be trace contaminants in low purity commercial $\mathrm{ZnO}$ targets, as the ones used in this work. Intrinsic defects such as $\mathrm{Zn}_{\mathrm{i}}, \mathrm{O}_{\mathrm{i}}, \mathrm{V}_{\mathrm{O}}, \mathrm{V}_{\mathrm{Zn}}$, and their complexes have been reported in the literature as being responsible for the unstructured broad emission bands in $\mathrm{ZnO}[38,39]$. When the growth conditions are performed under oxygen deficiency, as the case of $\mathrm{Z} 1$ sample, $\mathrm{V}_{\mathrm{O}}$ and $\mathrm{Zn}_{\mathrm{i}}$ are expected to be the main intrinsic point defects. However, first-principles calculations have shown that these defects have a high energy formation; consequently their occurrence is unlikely [40]. According to Janotti and Van de Walle [40] the neutral $\mathrm{V}_{\mathrm{O}}$ leads to a deep donor level located at $\sim 1 \mathrm{eV}$ below the conduction band,
$\mathrm{V}_{\mathrm{Zn}}$ are deep acceptors, and $\mathrm{Zn}_{\mathrm{i}}$ are shallow donors. The latter is also known to form unstable defects due to their low energy migration [40]. Nowadays, it has been widely accepted that $\mathrm{V}_{\mathrm{Zn}}$ (and their aggregates) are the most likely acceptors in $\mathrm{ZnO}$ [41-44], introducing energy levels between 1.6 and $2.1 \mathrm{eV}$ below the conduction band [44].

Previous studies have also shown a strong correlation between the screw dislocations and the near band edge PL intensity [45]. Namely, the generated strain fields around screw dislocations leading to heterogeneous spatial distribution of the carriers are known to disturb the density of states reducing the PL recombination efficiency. On the other hand, it has been pointed out that the edge dislocations assume an important role on the deep level emission in semiconductors by trapping point defects and impurities in their strain fields $[3,46]$.

As can be seen in Figure 9 (in logarithmic scale), besides the already stated transitions, a broad red band of unknown origin was detected in both samples, however, with a stronger emission in sample $\mathrm{Z1}$, which is the sample with the highest estimated value of the TD density $\left(\sim 10^{9} \mathrm{~cm}^{-2}\right)$. In order to establish a coherent interpretation of the $1.78 \mathrm{eV}$ emission, band temperature and excitation dependent PL studies were carried out for Z1 sample, presented in Figures 10 and 11.

The evolution of the red band PL intensity with temperature depicted in Figure 10(a) evidences a decrease in the overall intensity when the temperature increases. Furthermore, a shift to lower energy of the band maximum is observed for temperatures above $40 \mathrm{~K}$ (Figure 10(b)). By assuming a Gaussian band shape to fit the deep level recombination, the evolution of the integrated intensity of the red band can be established as shown in Figure 10(c). Considering a classical model to describe a single thermally activated nonradiative recombination channel, the evolution of the integrated intensity, $I(T)$, with temperature follows a Mott law according to

$$
I(T)=I_{0}\left[1+a \cdot \exp \left(-\frac{E_{a}}{k_{B}}\right)\right]^{-1},
$$

where $I_{0}$ stands for the low temperature intensity when the nonradiative processes are neglected; $a$ is a temperature independent effective degeneracy, $E_{a}$ is the activation energy for the nonradiative processes, and $k_{B}$ is the Boltzmann constant. The best fit is achieved for an activation energy of $14 \pm 2 \mathrm{meV}$.

It should be mentioned that similar broad red bands have been reported in bulk, films, and nanostructures of $\mathrm{ZnO}$ and GaN materials [38, 47]. Particularly, Reshchikov et al. [38] found in bulk material of $\mathrm{ZnO}$ an emission band (denoted as RL1) with the maximum near the same energy and a thermal quenching described by similar activation energy. However, while in the latter case no shifts of the RL1 band maximum were identified between $14 \mathrm{~K}$ and the RT, in our work the red luminescence maximum shifts following the band gap shrinkage (Figure 10(b)). This behaviour suggests that the defect related with the $1.78 \mathrm{eV}$ band should involve electronic energy levels sensitive to the band gap reduction, described by the effective mass theory. 


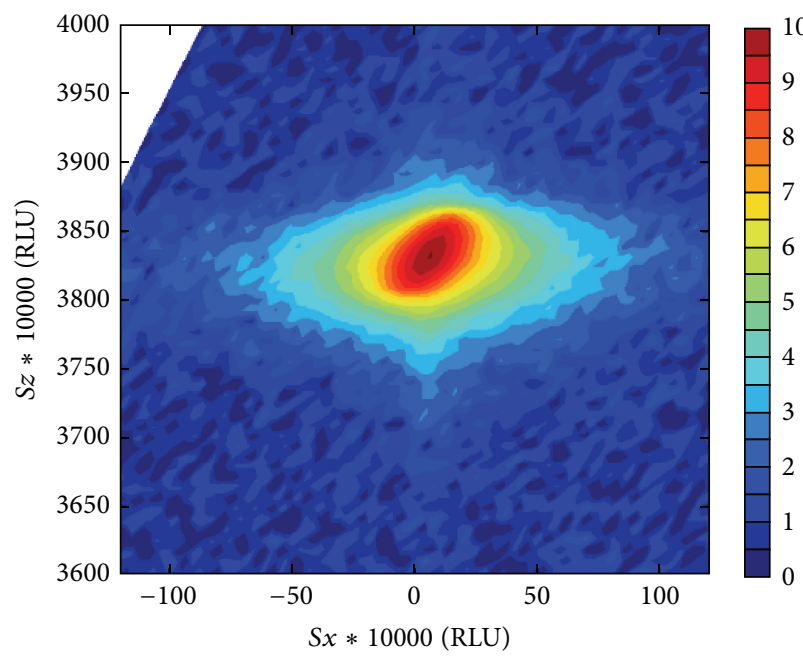

(a)

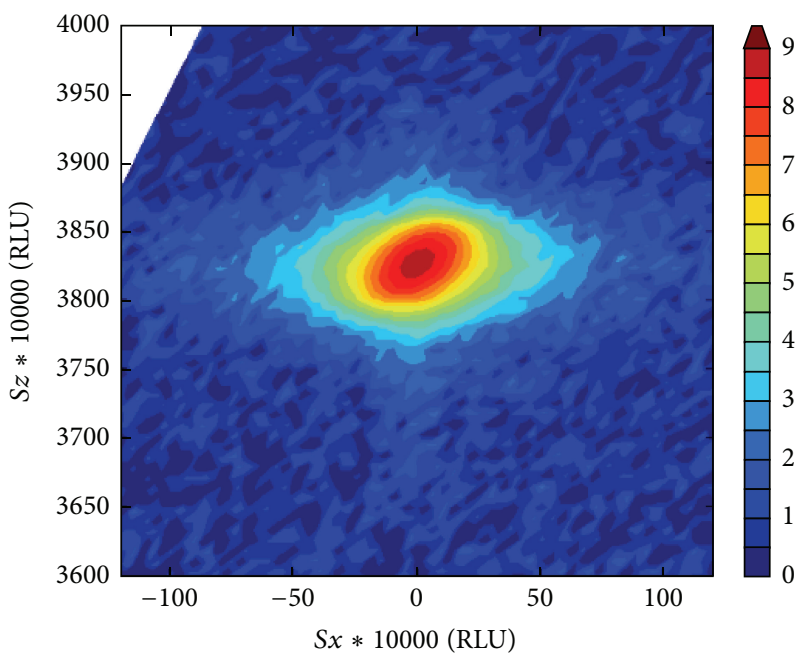

(b)

FIGURE 7: RSM of the (0002) symmetric reflections for (a) Z1 and (b) Z2 samples.

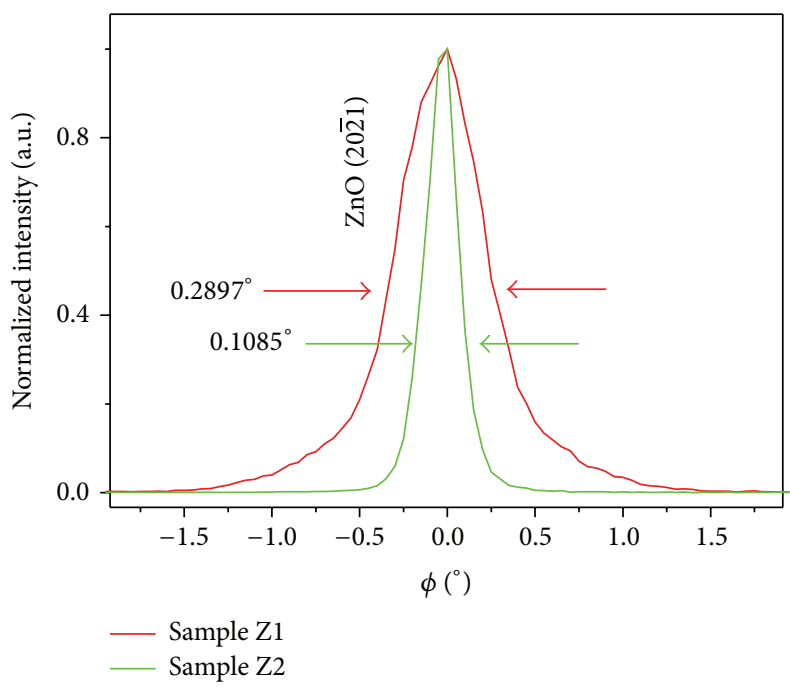

FIGURE 8: $\phi$-scans for $(20 \overline{2} 1)$ reflection obtained in skew geometry for samples Z1 (red) and Z2 (green).

Increasing the excitation density, the measured $14 \mathrm{~K}$ PL spectra (Figure 11(a)) promote a high energy shift of the band maximum. This is a common behaviour in DAP transitions due to the saturation of distant pairs, which have low transition probabilities [48]. In our case a $\sim 20 \mathrm{meV}$ shift can be observed among the low and high excitation intensities (Figure 11(b)). An additional indication that the red $1.78 \mathrm{eV}$ band behaves as a DAP transition is provided by the sublinear dependence (Figure 11(c)) of the integrated PL intensity with the excitation intensity $\left(I_{\mathrm{PL}} \alpha I_{\text {exc }}{ }^{\beta}\right)$ expected for this type of recombination processes [49]. The emission energy of a DAP $\left(E_{\mathrm{DAP}}\right)$ with a separation $r$ is given by [48]

$$
E_{\mathrm{DAP}}=E_{g}-E_{d}-E_{a}+\frac{e^{2}}{4 \pi \varepsilon_{0} \varepsilon_{r} r},
$$

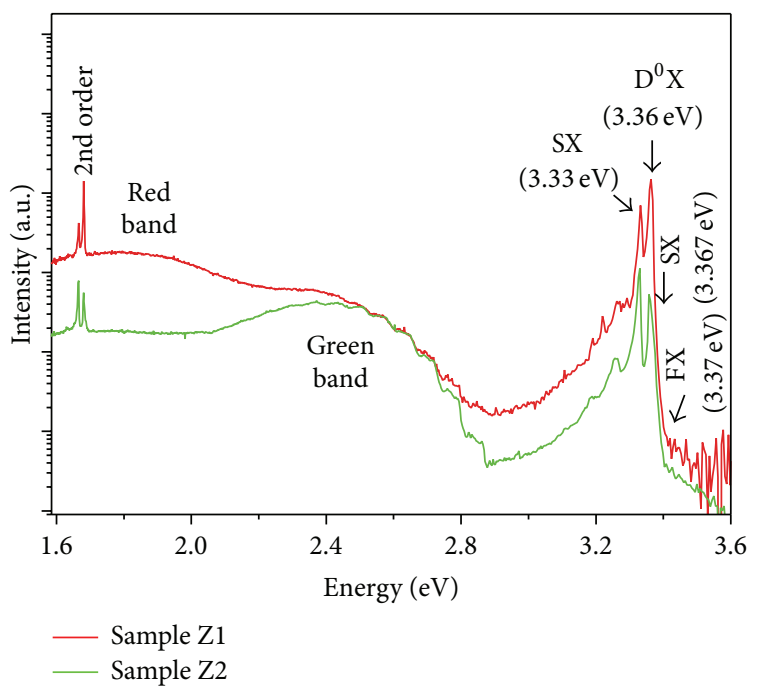

FIgure 9: The PL spectra of the Z1 (red) and Z2 (green) samples obtained by the $\mathrm{He}-\mathrm{Cd}$ excitation at $14 \mathrm{~K}$ (the spectra are presented in logarithmic scale).

where $E_{g}$ stands for the band gap energy, $E_{d}$ and $E_{a}$ stand for the donor and acceptor binding energies, and the $1 / r$ term corresponds to the Coulomb interaction among the ionized species.

Considering that under the low excitation intensity conditions an infinite pair separation is reached, the Coulomb term could be neglected, and an $\left(E_{a}+E_{d}\right) \sim 1.68 \mathrm{eV}$ is estimated by assuming a band gap energy of $3.437 \mathrm{eV}$ at $14 \mathrm{~K}$. If the $14 \mathrm{meV}$ determined from the red band quenching corresponds to the binding energy of an exciton bound to the donor $\left(E_{b, d}\right)$ by using the Haynes rule derived by Meyer et al. [9] for shallow donors, $E_{b, d}=0.365 E_{d}-3.8(\mathrm{meV})$, a donor binding energy of $\sim 49 \mathrm{meV}$ is estimated. This energy value suggests that $\mathrm{H}$ participate in DAP [9]. The acceptor 


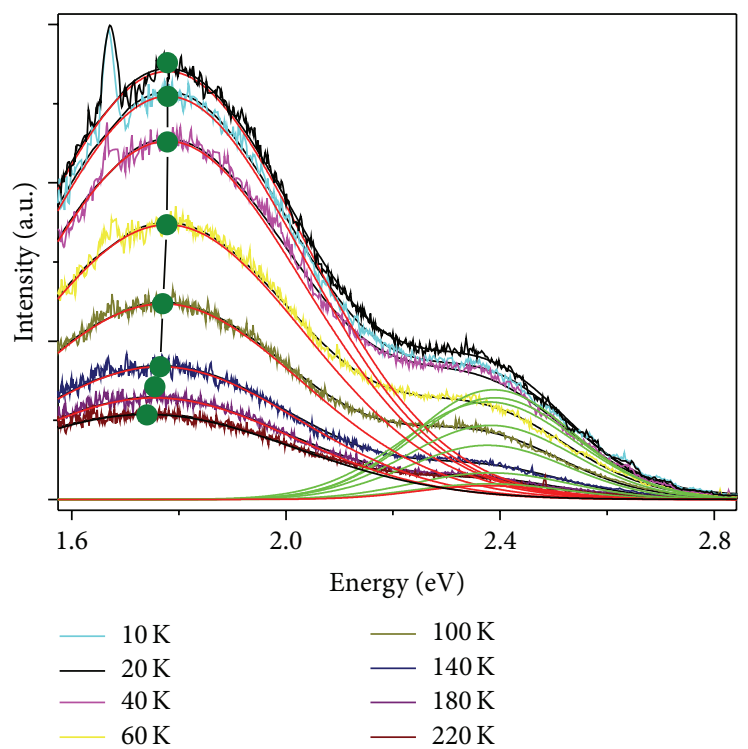

(a)

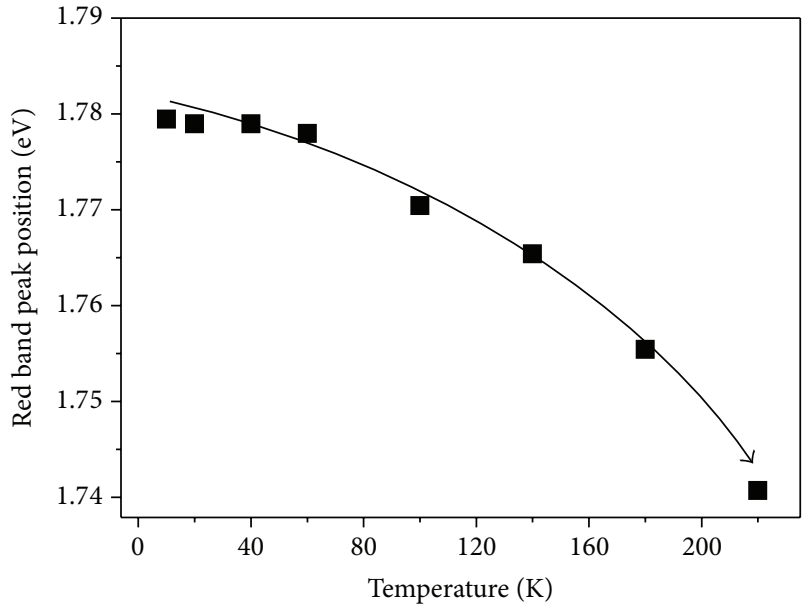

(b)

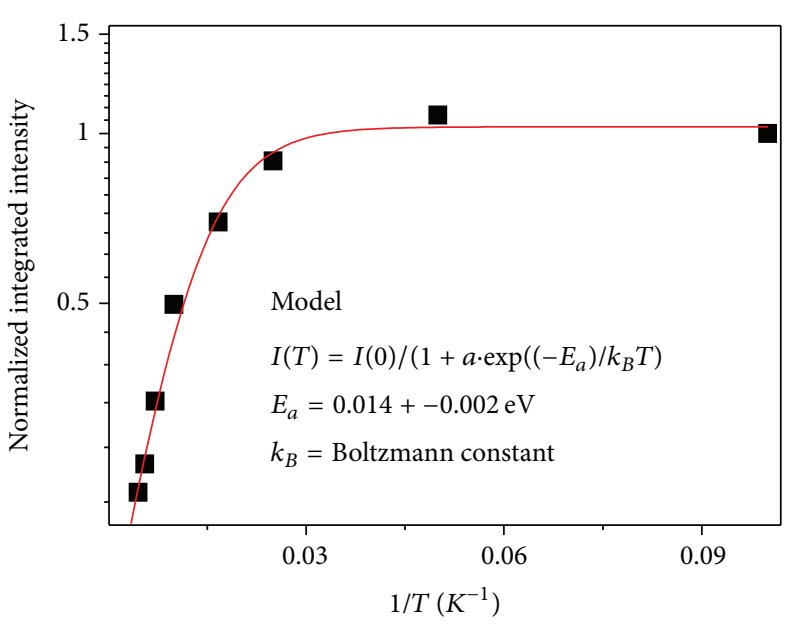

(c)

FIGURE 10: Sample Z1. (a) Temperature dependent deep level PL spectra obtained with above band gap excitation, (b) temperature dependence of the red band peak energy, and (c) dependence of the integrated emission intensity with the temperature for the red band.

level should be placed at $\sim 1.75 \mathrm{eV}$ above the valence band, if in agreement with the expected energy level for zinc vacancies [44]. Taking into account the discussion provided on the nature and energy level location of the intrinsic defects referred to above, the red emission band could be associated with a DAP involving the hydrogen shallow donor and zinc vacancies as deep acceptors. Consequently, the stronger intensity of the red emission for sample Z1 (with the higher TD density) suggests that higher amount of point defects could be induced in samples with the highest threading dislocations density.

\section{Conclusions}

In this work, $\mathrm{ZnO}$ films have been deposited on $c-\mathrm{Al}_{2} \mathrm{O}_{3}$ substrate under presence and absence of oxygen. These different oxygen pressures have strong effects on the structural and optical properties of $\mathrm{ZnO}$ layers. The films are monocrystalline with a highlighted quality. However, the TEM characterization has revealed that the sample grown without oxygen atmosphere presents a higher density of TDs, the majority of them being edge dislocations type. Moreover, it was found that both samples evidence heterogeneity in depth, displaying a decrease of the TD density from the sapphire/ $\mathrm{ZnO}$ interface to the sample surface. In agreement with the TEM results, the asymmetrical $\phi$-scans for $(20 \overline{2} 1)$ reflection reveal a high value of twist angle for the sample process with null oxygen pressure, indicating high density of edge dislocations. In addition by optical characterization, a green band at $\sim 2.4 \mathrm{eV}$ and a red band at $\sim 1.78 \mathrm{eV}$ are observed. The green structured band is similar to the one previously assigned to the presence of $\mathrm{Cu}_{\mathrm{Zn}}$ acceptor due to copper impurities likely due to trace contaminants in 


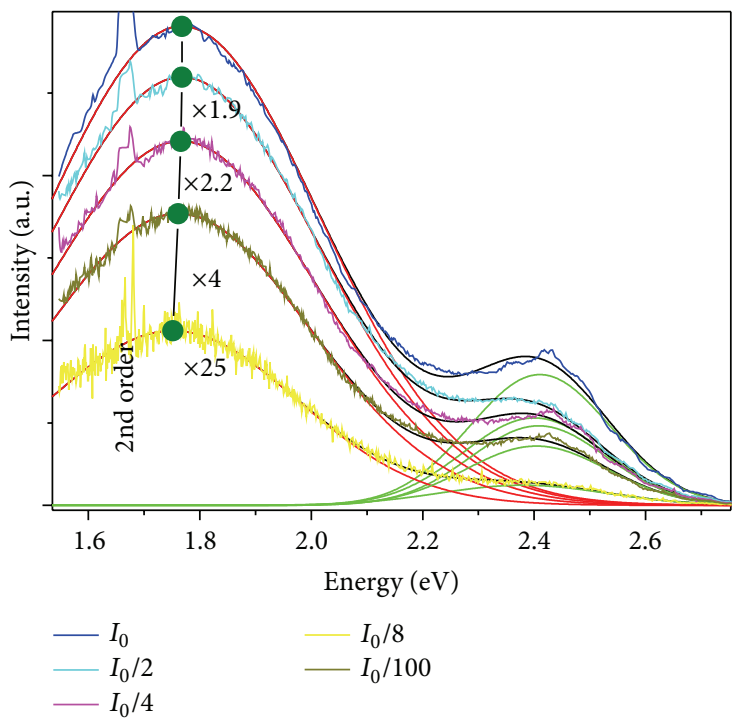

(a)

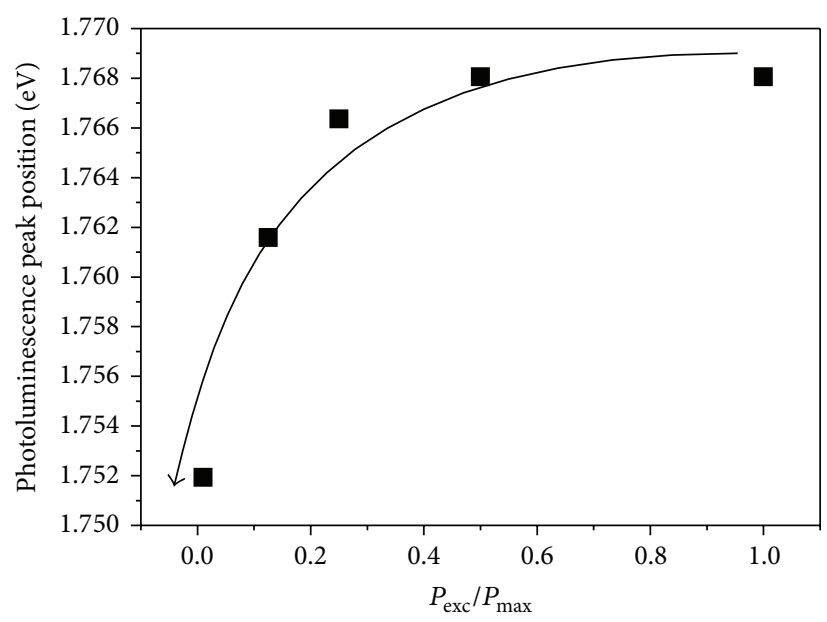

(b)

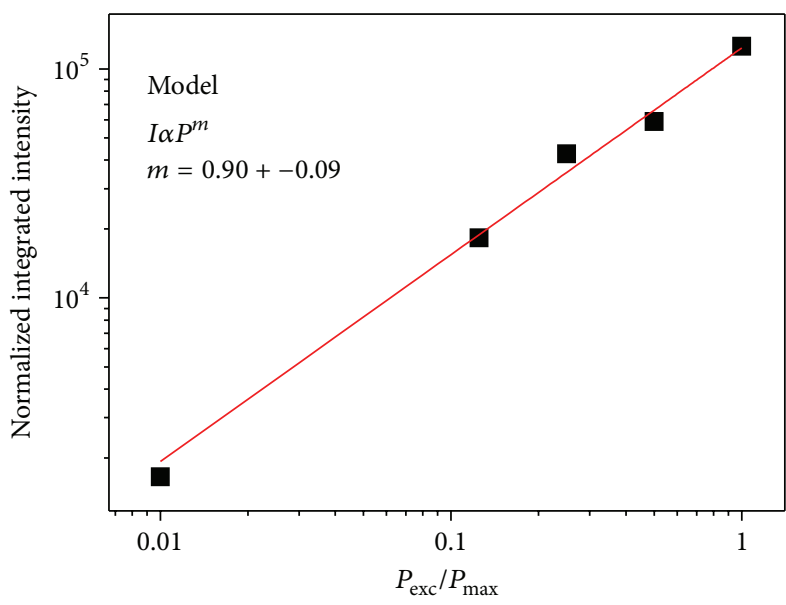

(c)

FIGURE 11: Sample Z1. (a) 14 K PL spectra obtained with above band gap excitation by using different excitation intensities, (b) red band peak energy dependence with the excitation intensity, and (c) dependence of the red band integrated intensity with the excitation intensity.

the precursor target. The red luminescence is more pronounced in the sample with the uppermost density of TDs. Hence, this red band has been analysed in detail, in order to find a correlation with the different amount of edge dislocations. From the temperature and excitation dependence of the red band, a donor acceptor pair recombination model has been proposed, where hydrogen and zinc vacancies are strong candidates for the donor and acceptor species, respectively. These results suggest that such optically active point defects are promoted in the sample with higher amount of edge dislocations.

\section{Conflict of Interests}

The authors declare that there is no conflict of interests regarding the publication of this paper.

\section{Acknowledgments}

This work was partially supported by Junta de Andalucía (Spain) with EU-FEDER cofinancing (PAI group TEP-120 and Project P09-TEP-5403). This work is funded by FEDER funds through the COMPETE 2020 Programme and National Funds through FCT-Portuguese Foundation for Science and Technology under Project UID/CTM/50025/2013. Besides, the authors acknowledge FCT for the funding through PTDC/CTM-NAN/2156/2012 and RECI/FIS-NAN/0183/2012 (FCOMP-01-0124-FEDER-027494) and SFRH/BD/45774/2008 projects from Portugal. The EU COST MP0805 is also acknowledged. In addition, thinning methods to produce electron transparency were performed in the Laboratory for Sample Preparations, and TEM analyses were carried out at the Division of Electron Microscopy, both at the UCA central facilities (SC-ICYT). 


\section{References}

[1] Z. K. Tang, G. K. L. Wong, P. Yu et al., "Room-temperature ultraviolet laser emission from self-assembled $\mathrm{ZnO}$ microcrystallite thin films," Applied Physics Letters, vol. 72, no. 25, pp. 3270-3272, 1998.

[2] U. Ozgur, Y. I. Alivov, C. Liu et al., "A comprehensive review of ZnO materials and devices," Journal of Applied Physics, vol. 98, no. 4, Article ID 041301, 2005.

[3] C. Y. Lin, W.-R. Liu, C. S. Chang, C.-H. Hsu, W. F. Hsieh, and F. S.-S. Chien, "Effect of threading dislocations on local contacts in epitaxial ZnO films," Journal of the Electrochemical Society, vol. 157, no. 3, pp. H268-H271, 2010.

[4] Z. L. Wang, "Towards self-powered nanosystems: from nanogenerators to nanopiezotronics," Advanced Functional Materials, vol. 18, no. 22, pp. 3553-3567, 2008.

[5] J. Zhou, Y. Gu, Y. Hu et al., "Gigantic enhancement in response and reset time of $\mathrm{ZnO}$ UV nanosensor by utilizing Schottky contact and surface functionalization," Applied Physics Letters, vol. 94, no. 19, Article ID 191103, 2009.

[6] K. Liu, M. Sakurai, and M. Aono, "ZnO-based ultraviolet photodetectors," Sensors, vol. 10, no. 9, pp. 8604-8634, 2010.

[7] U. Bangert, A. J. Harvey, R. Jones et al., "Dislocation-induced electronic states and point-defect atmospheres evidenced by electron energy loss imaging," New Journal of Physics, vol. 6, 2004.

[8] Y. Ohno, H. Koizumi, T. Taishi et al., "Optical properties of dislocations in wurtzite $\mathrm{ZnO}$ single crystals introduced at elevated temperatures," Journal of Applied Physics, vol. 104, no. 7, Article ID 073515, 2008.

[9] B. K. Meyer, H. Alves, D. M. Hofmann et al., "Bound exciton and donor-acceptor pair recombinations in ZnO," Physica Status Solidi B: Basic Research, vol. 241, no. 2, pp. 231-260, 2004.

[10] V. Khranovskyy, M. O. Eriksson, G. Z. Radnoczi et al., "Photoluminescence study of basal plane stacking faults in $\mathrm{ZnO}$ nanowires," Physica B: Condensed Matter, vol. 439, pp. 50-53, 2014.

[11] D. O. Dumcenco, Y. S. Huang, D. H. Kuo, and K. K. Tiong, "Photoluminescence characterization of vertically aligned $\mathrm{ZnO}$ microrods," Journal of Luminescence, vol. 132, no. 8, pp. 18901895, 2012.

[12] J. Rodrigues, T. Holz, R. Fath Allah et al., "Effect of $\mathrm{N}_{2}$ and $\mathrm{H}_{2}$ plasma treatments on band edge emission of $\mathrm{ZnO}$ microrods," Scientific Reports, vol. 5, Article ID 10783, 2015.

[13] T. Monteiro, A. J. Neves, M. C. Carmo et al., "Near-band-edge slow luminescence in nominally undoped bulk $\mathrm{ZnO}$," Journal of Applied Physics, vol. 98, no. 1, Article ID 013502, 2005.

[14] M. Peres, S. Magalhães, M. R. Soares et al., "Disorder induced violet/blue luminescence in rf-deposited $\mathrm{ZnO}$ films," Physica Status Solidi (C), vol. 10, no. 4, pp. 662-666, 2013.

[15] N. Bano, I. Hussain, O. Nur, M. Willander, P. Klason, and A. Henry, "Study of luminescent centers in $\mathrm{ZnO}$ nanorods catalytically grown on $4 \mathrm{H}-\mathrm{p}-\mathrm{SiC}$," Semiconductor Science and Technology, vol. 24, no. 12, Article ID 125015, 2009.

[16] C. H. Ahn, Y. Y. Kim, D. C. Kim, S. K. Mohanta, and H. K. Cho, "A comparative analysis of deep level emission in $\mathrm{ZnO}$ layers deposited by various methods," Journal of Applied Physics, vol. 105, no. 1, Article ID 013502, 2009.

[17] A. B. Djurišić, Y. H. Leung, K. H. Tam et al., "Green, yellow, and orange defect emission from $\mathrm{ZnO}$ nanostructures: influence of excitation wavelength," Applied Physics Letters, vol. 88, no. 10, Article ID 103107, 2006.
[18] R. Bhaskar, A. R. Lakshmanan, M. Sundarrajan, T. Ravishankar, M. T. Jose, and N. Lakshminarayan, "Mechanism of green luminescence in ZnO," Indian Journal of Pure \& Applied Physics, vol. 47, no. 11, pp. 772-774, 2009.

[19] G. Xiong, K. B. Ucer, R. T. Williams et al., "Donor-acceptor pair luminescence of nitrogen-implanted $\mathrm{ZnO}$ single crystal," Journal of Applied Physics, vol. 97, no. 4, Article ID 043528, 2005.

[20] M. Schirra, R. Schneider, A. Reiser et al., "Stacking fault related 3.31-eV luminescence at $130-\mathrm{meV}$ acceptors in zinc oxide," Physical Review B-Condensed Matter and Materials Physics, vol. 77, no. 12, Article ID 125215, 2008.

[21] Q. X. Zhao, M. Willander, R. E. Morjan, Q-H. Hu, and E. E. B. Campbell, "Optical recombination of $\mathrm{ZnO}$ nanowires grown on sapphire and Si substrates," Applied Physics Letters, vol. 83, no. 1, pp. 165-167, 2003.

[22] T. Makino, Y. Segawa, S. Yoshida, A. Tsukazaki, A. Ohtomo, and M. Kawasaki, "Gallium concentration dependence of roomtemperature near-band-edge luminescence in n-type $\mathrm{ZnO}: \mathrm{Ga}$," Applied Physics Letters, vol. 85, no. 5, pp. 759-761, 2004.

[23] J. M. Mánuel, F. M. Morales, R. García, R. Aidam, L. Kirste, and O. Ambacher, "Threading dislocation propagation in AlGaN/GaN based HEMT structures grown on Si (111) by plasma assisted molecular beam epitaxy," Journal of Crystal Growth, vol. 357, no. 1, pp. 35-41, 2012.

[24] J. W. Edington, Practical Electron Microscopy in Material Science, MacMillan Press, Eindhoven, The Netherlands, 1975.

[25] D. M. Follstaedt, N. A. Missert, D. D. Koleske, C. C. Mitchell, and K. C. Cross, "Plan-view image contrast of dislocations in GaN," Applied Physics Letters, vol. 83, no. 23, pp. 4797-4799, 2003.

[26] F. Vigué, P. Vennéguès, S. Vézian, M. Laügt, and J.-P. Faurie, "Defect characterization in $\mathrm{ZnO}$ layers grown by plasmaenhanced molecular-beam epitaxy on (0001) sapphire substrates," Applied Physics Letters, vol. 79, no. 2, pp. 194-196, 2001.

[27] W.-R. Liu, W. F. Hsieh, C.-H. Hsu, K. S. Liang, and F. S.-S. Chien, "Threading dislocations in domain-matching epitaxial films of ZnO," Journal of Applied Crystallography, vol. 40, no. 5, pp. 924930, 2007.

[28] W.-R. Liu, B. H. Lin, S. Yang et al., “The influence of dislocations on optical and electrical properties of epitaxial $\mathrm{ZnO}$ on $\mathrm{Si}$ (111) using a $\gamma-\mathrm{Al}_{2} \mathrm{O}_{3}$ buffer layer," CrystEngComm, vol. 14, no. 5, pp. 1665-1671, 2012.

[29] Y. B. Zhang, G. K. L. Goh, and S. Li, "Reduction of threading dislocations in hydrothermally grown $\mathrm{ZnO}$ films by lateral epitaxial overgrowth," Thin Solid Films, vol. 518, no. 24, pp. E104-E106, 2010.

[30] Y. Sawai, K. Hazu, and S. F. Chichibu, "Surface stoichiometry and activity control for atomically smooth low dislocation density $\mathrm{ZnO}$ and pseudomorphic $\mathrm{MgZnO}$ epitaxy on a $\mathrm{Zn}$-polar $\mathrm{ZnO}$ substrate by the helicon-wave-excited-plasma sputtering epitaxy method," Journal of Applied Physics, vol. 108, no. 6, Article ID 063541, 2010.

[31] M. A. Moram and M. E. Vickers, "X-ray diffraction of IIInitrides," Reports on Progress in Physics, vol. 72, no. 3, 2009.

[32] T. Metzger, R. Höpler, E. Born et al., "Defect structure of epitaxial GaN films determined by transmission electron microscopy and triple-axis X-ray diffractometry," Philosophical Magazine A: Physics of Condensed Matter, Structure, Defects and Mechanical Properties, vol. 77, no. 4, pp. 1013-1025, 1998.

[33] K. Thonke, T. Gruber, N. Teofilov, R. Schönfelder, A. Waag, and R. Sauer, "Donor-acceptor pair transitions in $\mathrm{ZnO}$ substrate 
material," Physica B: Condensed Matter, vol. 308-310, pp. 945948, 2001.

[34] L. Wischmeier, T. Voss, I. Rückmann et al., "Dynamics of surface-excitonic emission in $\mathrm{ZnO}$ nanowires," Physical Review B, vol. 74, no. 19, Article ID 195333, 2006.

[35] J. Grabowska, A. Meaney, K. K. Nanda et al., "Surface excitonic emission and quenching effects in $\mathrm{ZnO}$ nanowire/nanowall systems: limiting effects on device potential," Physical Review B, vol. 71, no. 11, Article ID 115439, 2005.

[36] K. Thonke, M. Schirra, R. Schneider et al., "The role of stacking faults and their associated 0.13 ev acceptor state in doped and undoped $\mathrm{ZnO}$ layers and nanostructures," Microelectronics Journal, vol. 40, no. 2, pp. 210-214, 2009.

[37] R. Dingle, "Luminescent transitions associated with divalent copper impurities and the green emission from semiconducting zinc oxide," Physical Review Letters, vol. 23, no. 11, pp. 579-581, 1969.

[38] M. A. Reshchikov, H. Morkoç, B. Nemeth et al., "Luminescence properties of defects in $\mathrm{ZnO}$," Physica B: Condensed Matter, vol. 401-402, pp. 358-361, 2007.

[39] M. D. McCluskey and S. J. Jokela, "Defects in ZnO," Journal of Applied Physics, vol. 106, no. 7, Article ID 071101, 2009.

[40] A. Janotti and C. G. Van de Walle, "Native point defects in ZnO," Physical Review B-Condensed Matter and Materials Physics, vol. 76, no. 16, Article ID 165202, 2007.

[41] L. A. Kappers, O. R. Gilliam, S. M. Evans, L. E. Halliburton, and N. C. Giles, "EPR and optical study of oxygen and zinc vacancies in electron-irradiated ZnO," Nuclear Instruments and Methods in Physics Research B: Beam Interactions with Materials and Atoms, vol. 266, no. 12-13, pp. 2953-2957, 2008.

[42] A. K. Das, P. Misra, R. Kumar et al., "Studies on highly resistive $\mathrm{ZnO}$ thin films grown by DC-discharge-assisted pulsed laser deposition," Applied Physics A: Materials Science \& Processing, vol. 114, no. 4, pp. 1119-1128, 2014.

[43] L. M. Kukreja, P. Misra, J. Fallert, D. M. Phase, and H. Kalt, "Correlation of spectral features of photoluminescence with residual native defects of $\mathrm{ZnO}$ thin films annealed at different temperatures," Journal of Applied Physics, vol. 112, no. 1, Article ID 013525, 2012.

[44] Y. Dong, F. Tuomisto, B. G. Svensson, A. Y. Kuznetsov, and L. J. Brillson, "Vacancy defect and defect cluster energetics in ion-implanted ZnO," Physical Review B - Condensed Matter and Materials Physics, vol. 81, no. 8, Article ID 081201, 2010.

[45] D. G. Zhao, D. S. Jiang, H. Yang et al., "Role of edge dislocations in enhancing the yellow luminescence of $n$-type GaN," Applied Physics Letters, vol. 88, no. 24, Article ID 241917, 2006.

[46] A. Stroud and J. H. You, "Edge dislocation effect on optical properties in wurtzite ZnO," Journal of Crystal Growth, vol. 340, no. 1, pp. 92-97, 2012.

[47] M. A. Reshchikov, A. Usikov, H. Helava, and Y. Makarov, "Fine structure of the red luminescence band in undoped GaN," Applied Physics Letters, vol. 104, no. 3, Article ID 032103, 2014.

[48] M. A. Reshchikov and H. Morkoç, "Luminescence properties of defects in GaN," Journal of Applied Physics, vol. 97, no. 6, Article ID 061301, 2005.

[49] T. Schmidt, K. Lischka, and W. Zulehner, "Excitation-power dependence of the near-band-edge photoluminescence of semiconductors," Physical Review B, vol. 45, no. 16, pp. 8989-8994, 1992. 

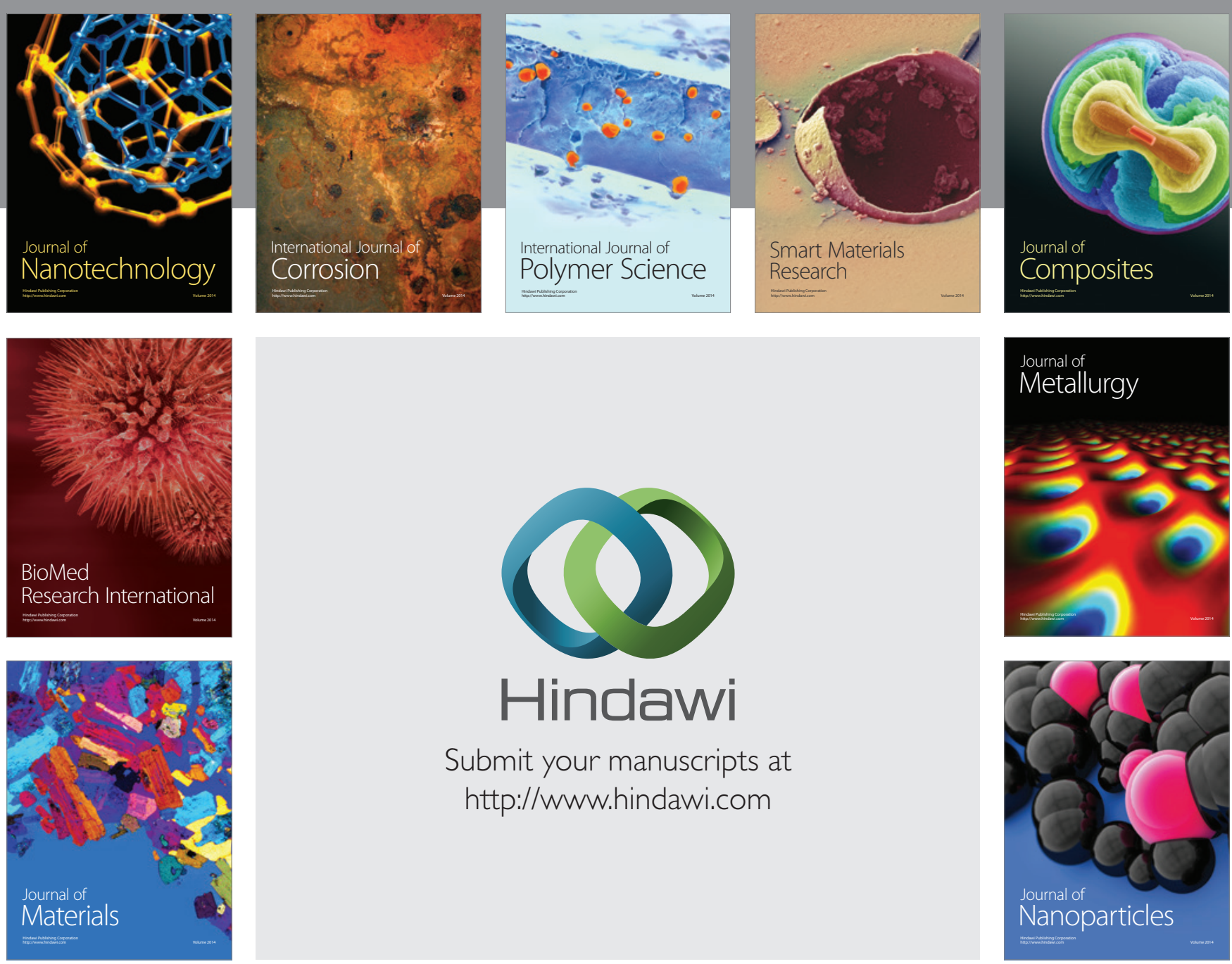

Submit your manuscripts at http://www.hindawi.com
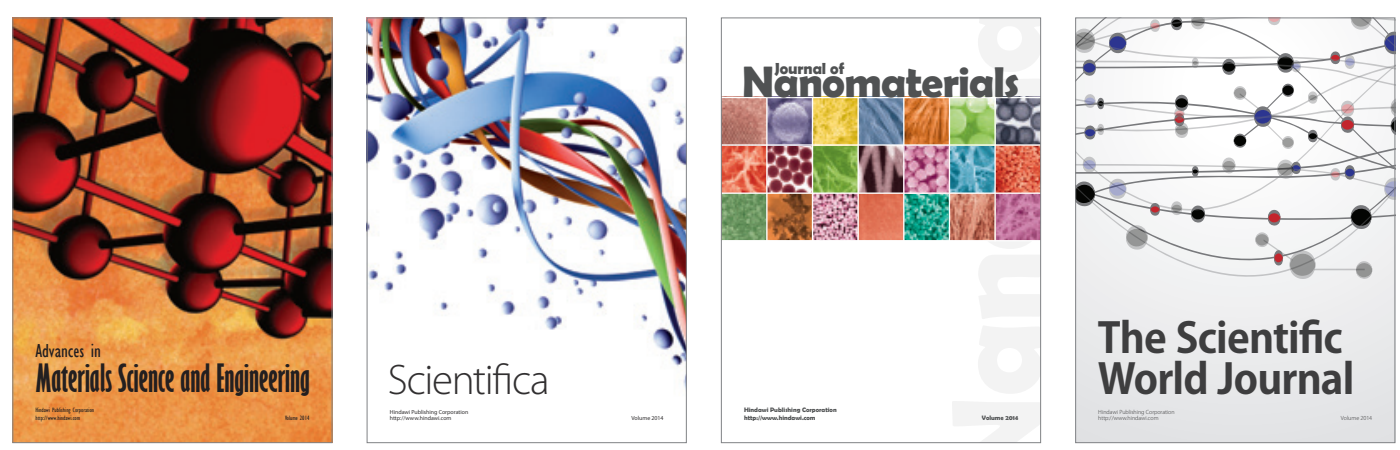

\section{The Scientific World Journal}
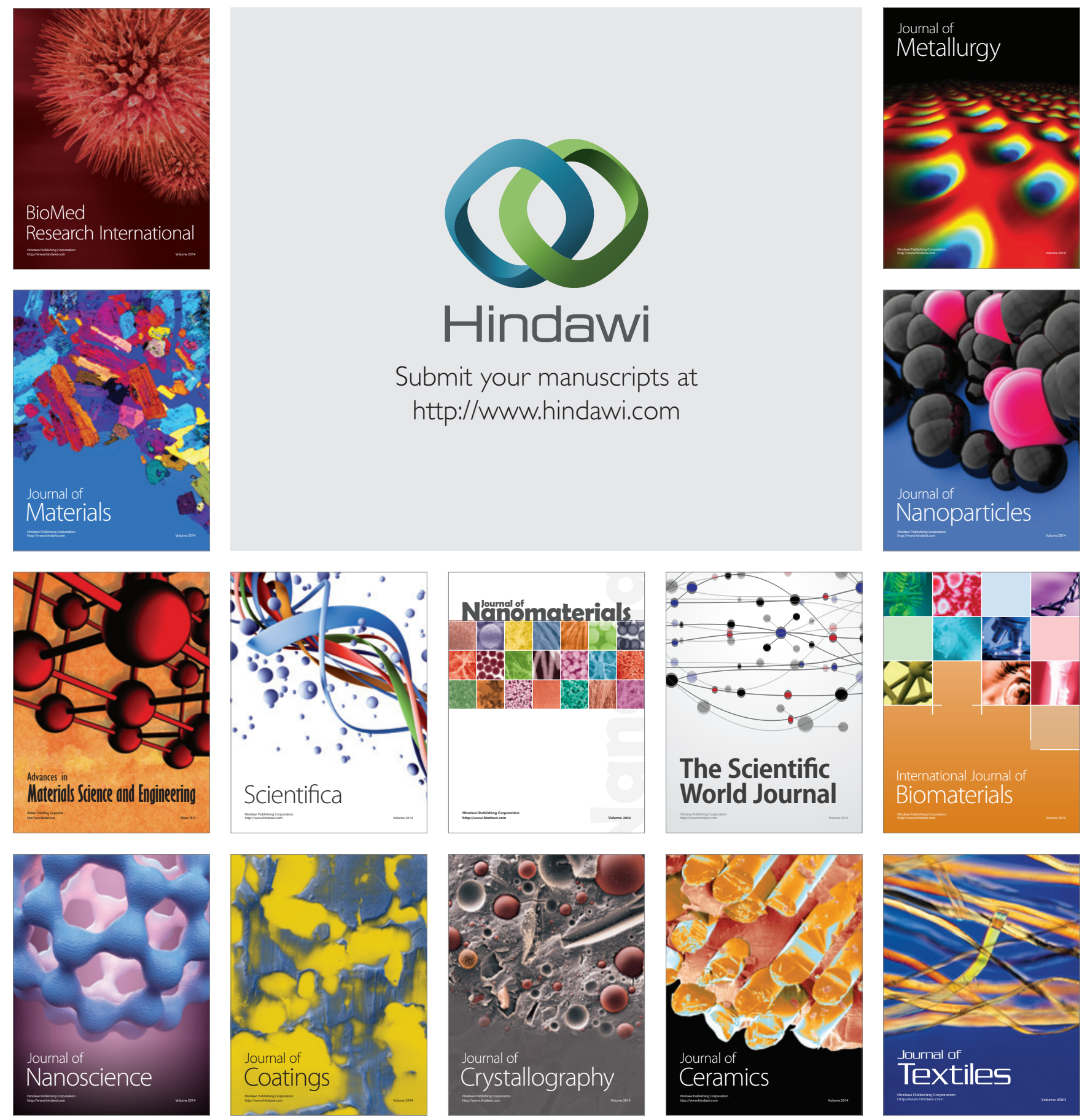